\title{
Five-level Direct Torque Control with Balancing Strategy of Double Star Induction Machine
}

\author{
Elakhdar Benyoussef, Said Barkat \\ University Kasdi Merbah of Ouargla 30000
}

Algeria

\begin{abstract}
This work relates to the study of direct torque control of the double star induction machine drive fed by two five-level diode-clamped inverters. The analysis of the three-phase direct torque control shows that this concept can be extended easily to double star induction machine even when it is fed by a multilevel inverter. Diode-clamped inverter, as one of the prominent multilevel inverters, has several advantages like high voltage and low current waveform distortion. However, it suffers from the problem of neutral point potential variation. The variation causes an unbalance in the DC-link voltage levels and increases consequently the current waveform distortion. This problem can be solved in satisfactory way by using multilevel direct torque control equipped by a balancing strategy. The simulation results, illustrating the steady state and dynamic performances, prove the effectiveness of the proposed control approach.
\end{abstract}

Keywords - Double star induction machine, Five-level diode clamped inverter, Direct torque control, Balancing strategy.

\section{INTRODUCTION}

$\mathrm{M}$ ULTIPHASE machines have been studied for a long time, but recently they have gained attention in the research community and industry worldwide [1]. The multiphase machines are used in wind power systems, electrical and hybrid vehicles, electric ship propulsion, electric aircraft actuators, and in safety-critical applications, such as aerospace or military naval drives, where fault tolerance is a desirable feature [2].

Multiphase machines drives have been proposed for different applications where some specific advantages such as: lower torque pulsations, less DC-link current harmonics, higher overall system reliability, better power distribution per phase can be better exploited, justifying the higher complexity in contrast to the three-phase solution [3].

One of the most common examples of multiphase machines is the double star induction machine (DSIM) [4]. This type of machine is composed of two windings with 30 electrical degrees phase shift and of a rotor, which can be wound or with squirrel cage. These windings are generally fed by a six-phase inverter supply in variable drives.

Multilevel inverter topology can offer reduced harmonic distortions of the output currents, low voltage stresses of power switches, and reduced electromagnetic interferences [5]. Therefore, it is a preferred solution for medium-high voltage or high-power electrical drives applications. Several topologies of multilevel inverters have been proposed in the specialized literatures [6]. Among these topologies, diodeclamped inverter (DCI) represents one of the most interesting solutions to increase voltage and power levels and to achieve high quality voltage waveforms. Unfortunately, DCI has an inherent problem of DC-link capacitors voltages variations [7]. Some solutions have been proposed, which are based on redundant switching configurations or on the addition of zerosequence voltage components to the output voltage references [8].

Direct torque control (DTC) has been actively investigated during the last decade in the area of $\mathrm{AC}$ drives. The main advantages of DTC are the high performance achieved by decoupling the control of stator flux and torque, fast torque response and robustness. Not only that, DTC is known by its simplicity since the coordinate transformation, modulation block, and current controllers are no longer requires [9]. In the basis DTC scheme, based on two-level inverter, the torque and flux ripples are high due to the limited number of voltage vectors. In order to overcome this problem, many contributions have been made that extent DTC to multilevel topologies [10].

The purpose of this paper is to propose a five-level DTC method with balancing strategy based on the redundancy of switching states in order to accomplish two objectives: (1) balancing the DC-link capacitors voltages; (2) ensuring a high performance of the multiphase drive.

The remainder of this paper is structured as follows: in Section II the model of the DSIM is presented, a suitable transformation matrix is used to develop a simple dynamic model. The proposed five-level DCI is briefly presented in section III. In section IV, the DTC strategy is applied to get decoupled control of the stator flux and electromagnetic torque. The simulation results related to the five-level DTC without balancing strategy are presented and discussed in the section V. The section VI is reserved to balancing analysis of the proposed control strategy. In the section VII, the simulation results related to the five-level DTC with balancing strategy are presented and discussed.

\section{DOUBLE Star INDUCtion Machine Modeling}

The machine model presented in this section is based on the following assumptions: The air gap is uniform and the windings are sinusoidally distributed around the air gap, and the magnetic saturation and core losses are neglected. A schematic of the stator and rotor windings for a double star induction machine is given in Fig. 1 [4]. 


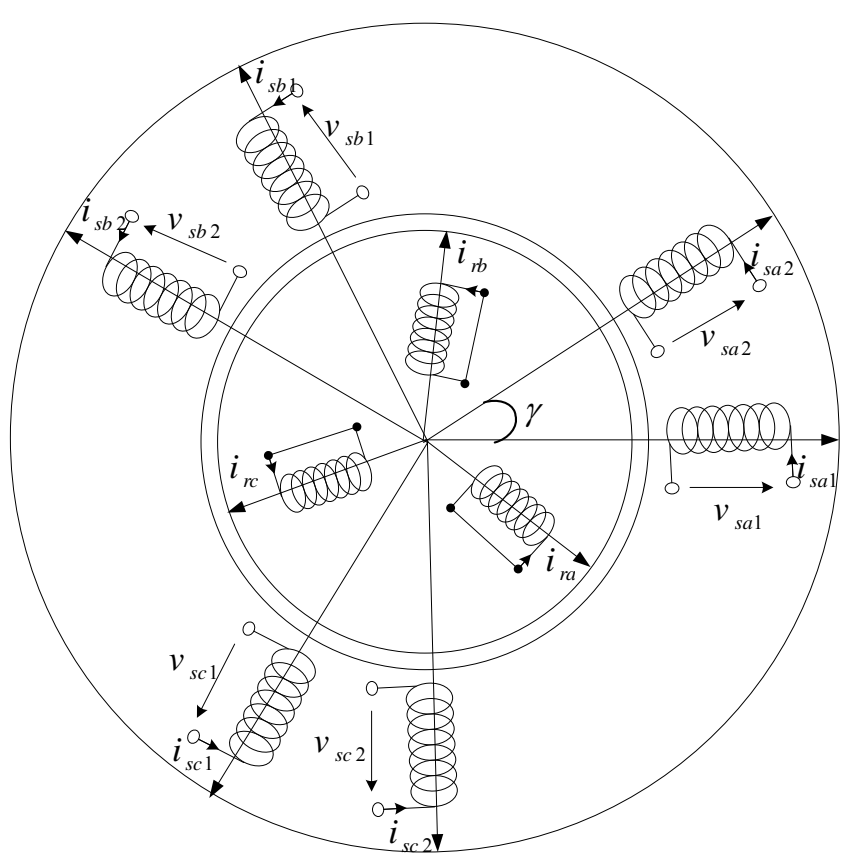

Fig. 1 DSIM windings representation.

The voltage equations in the original phase coordinates can be expressed as:

$$
\left\{\begin{array}{l}
v_{s 1}=R_{s} i_{s 1}+\frac{d \phi_{s 1}}{d t} \\
v_{s 2}=R_{s} i_{s 2}+\frac{d \phi_{s 2}}{d t} \\
0=R_{r} i_{r}+\frac{d \phi_{r}}{d t}
\end{array}\right.
$$

with:

$v_{s 1}=\left[\begin{array}{lll}v_{s a 1} & v_{s b 1} & v_{s c 1}\end{array}\right]^{T}:$ Stator voltages of the first winding;

$v_{s 2}=\left[\begin{array}{lll}v_{s a 2} & v_{s b 2} & v_{s c 2}\end{array}\right]^{T}$ : Stator voltages of the second winding; $i_{s 1}=\left[\begin{array}{lll}i_{s a 1} & i_{s b 1} & i_{s c 1}\end{array}\right]^{T}:$ Stator currents of the first winding; $i_{s 2}=\left[\begin{array}{lll}i_{s a 2} & i_{s b 2} & i_{s c 2}\end{array}\right]^{T}:$ Stator currents of the second winding; $i_{r}=\left[\begin{array}{lll}i_{r a} & i_{r b} & i_{r c}\end{array}\right]^{T} \quad$ : Rotor current;

$\phi_{s 1}=\left[\begin{array}{lll}\phi_{s a 1} & \phi_{s b 1} & \phi_{s c 1}\end{array}\right]^{T} \quad$ : Stator flux of the first winding;

$\phi_{s 2}=\left[\begin{array}{lll}\phi_{s a 2} & \phi_{s b 2} & \phi_{s c 2}\end{array}\right]^{T}$ : Stator flux of the second winding;

$\phi_{r}=\left[\begin{array}{lll}\phi_{r a} & \phi_{r b} & \phi_{r c}\end{array}\right]^{T} \quad$ : Rotor flux;

$R_{s}=\operatorname{Diag}\left[\begin{array}{lll}R_{s} & R_{s} & R_{s}\end{array}\right]:$ Stator resistance matrix for each star;

$R_{r}=\operatorname{Diag}\left[\begin{array}{lll}R_{r} & R_{r} & R_{r}\end{array}\right]$ : Rotor resistance matrix for each star.

The original six-dimensional stator system can be decomposed into three two-dimensional decoupled subsystems $(\alpha, \beta), \quad\left(z_{1}, z_{2}\right)$ and $\left(z_{3}, z_{4}\right)$, using the following transformation:

$$
\left[\begin{array}{llllll}
X_{s \alpha} & X_{s \beta} & X_{z 1} & X_{z 2} & X_{z 3} & X_{z 4}
\end{array}\right\rfloor=[A]\left[X_{s}\right]
$$

with

$$
\left[X_{s}\right]=\left[\begin{array}{ll}
X_{s 1} & X_{s 2}
\end{array}\right]^{T}=\left[\begin{array}{llllll}
X_{s a 1} & X_{s b 1} & X_{s c 1} & X_{s a 2} & X_{s b 2} & X_{s c 2}
\end{array}\right]^{T}
$$

where $X_{s}$ can refer to stator currents $\left(i_{s}\right)$, stator flux $\left(\phi_{s}\right)$, or stator voltages $\left(v_{s}\right)$. The matrix $A$ is given by:

$$
[A]=\frac{1}{\sqrt{3}}\left[\begin{array}{rrrrrr}
\cos (0) & \cos \left(\frac{2 \pi}{3}\right) & \cos \left(\frac{4 \pi}{3}\right) & \cos (\gamma) & \cos \left(\frac{2 \pi}{3}+\gamma\right) & \cos \left(\frac{4 \pi}{3}+\gamma\right) \\
\sin (0) & \sin \left(\frac{2 \pi}{3}\right) & \sin \left(\frac{4 \pi}{3}\right) & \sin (\gamma) & \sin \left(\frac{2 \pi}{3}+\gamma\right) & \sin \left(\frac{4 \pi}{3}+\gamma\right) \\
\cos (0) & \cos \left(\frac{4 \pi}{3}\right) & \cos \left(\frac{2 \pi}{3}\right) & \cos (\pi-\gamma) & \cos \left(\frac{\pi}{3}-\gamma\right) & \cos \left(\frac{5 \pi}{3}-\gamma\right) \\
\sin (0) & \sin \left(\frac{4 \pi}{3}\right) & \sin \left(\frac{2 \pi}{3}\right) & \sin (\pi-\gamma) & \sin \left(\frac{\pi}{3}-\gamma\right) & \sin \left(\frac{5 \pi}{3}-\gamma\right) \\
1 & 1 & 1 & 0 & 0 & 0 \\
0 & 0 & 0 & 1 & 1 & 1
\end{array}\right](3)
$$

The stator and rotor voltage equations in $\alpha-\beta$ reference frame are as follows:

$$
\left\{\begin{array}{l}
v_{s \alpha}=R_{s} i_{s \alpha}+\frac{d \phi_{s \alpha}}{d t} \\
v_{s \beta}=R_{s} i_{s \beta}+\frac{d \phi_{s \beta}}{d t} \\
0=R_{s} i_{r \alpha}+\frac{d \phi_{r \alpha}}{d t}+\Omega p \phi_{r \beta} \\
0=R_{s} i_{r \beta}+\frac{d \phi_{r \beta}}{d t}-\Omega p \phi_{r \alpha}
\end{array}\right.
$$

with:

$v_{s \alpha}, v_{s \beta}$ : The $\alpha-\beta$ components of stator voltage;

$i_{s \alpha}, i_{s \beta}:$ The $\alpha-\beta$ components of stator currents;

$i_{r \alpha}, i_{r \beta}$ : The $\alpha-\beta$ components of rotor currents;

$\phi_{s \alpha}, \phi_{s \beta}:$ The $\alpha-\beta$ components of stator flux;

$\phi_{r \alpha}, \phi_{r \beta}$ : The $\alpha-\beta$ components of rotor flux.

The stator voltage equations in $z_{1}-z_{2}$ and $z_{3}-z_{4}$ reference frame are as follows:

$$
\left[\begin{array}{l}
v_{z 1} \\
v_{z 2} \\
v_{z 3} \\
v_{z 4}
\end{array}\right]=R_{s}\left[\begin{array}{l}
i_{z 1} \\
i_{z 2} \\
i_{z 3} \\
i_{z 4}
\end{array}\right]+\left[\begin{array}{cccc}
l_{s} & 0 & 0 & 0 \\
0 & l_{s} & 0 & 0 \\
0 & 0 & l_{s} & 0 \\
0 & 0 & 0 & l_{s}
\end{array}\right] \frac{d}{d t}\left[\begin{array}{l}
i_{z 1} \\
i_{z 2} \\
i_{z 3} \\
i_{z 4}
\end{array}\right]
$$

The harmonic currents $i_{z 1}$ and $i_{z 2}$ must be as low as possible to reduce the extra losses in the DSIM. These currents are only limited by stator resistance and leakage inductance.

The currents $i_{z 3}$ and $i_{z 4}$ are equal to zero because the two three-phase windings are connected with isolated neutrals.

The electromagnetic torque is given as:

$$
T_{e m}=p\left(\phi_{s \alpha} i_{s \beta}-\phi_{s \beta} i_{s \alpha}\right)
$$




\section{FIVE-LEVEL INVERTER MODELING}

Fig. 2 shows a schematic diagram of a three-phase five-level diode-clamped inverter. In this circuit, the DC-bus voltage is split into five levels by four series-connected capacitors, $C_{1}$, $C_{2}, C_{3}$, and $C_{4}$. There are four complimentary switch pairs in each phase. For a complimentary switch pair, turning on one of the switches excludes the other from being turned on. Using phase-a as an example, the four complementary pairs are $\left(S_{k a 1}, S_{k a 5}\right),\left(S_{k a 2}, S_{k a 6}\right),\left(S_{k a 3}, S_{k a 7}\right)$, and $\left(S_{k a 4}, S_{k a 8}\right)$.

Gating signals $S_{k x 5}, S_{k x 6}, S_{k x 7}$ and $S_{k x 8}$ are simply generated by inverting $S_{k x 1}, S_{k x 2}, S_{k x 3}$ and $S_{k x 4}$, respectively.

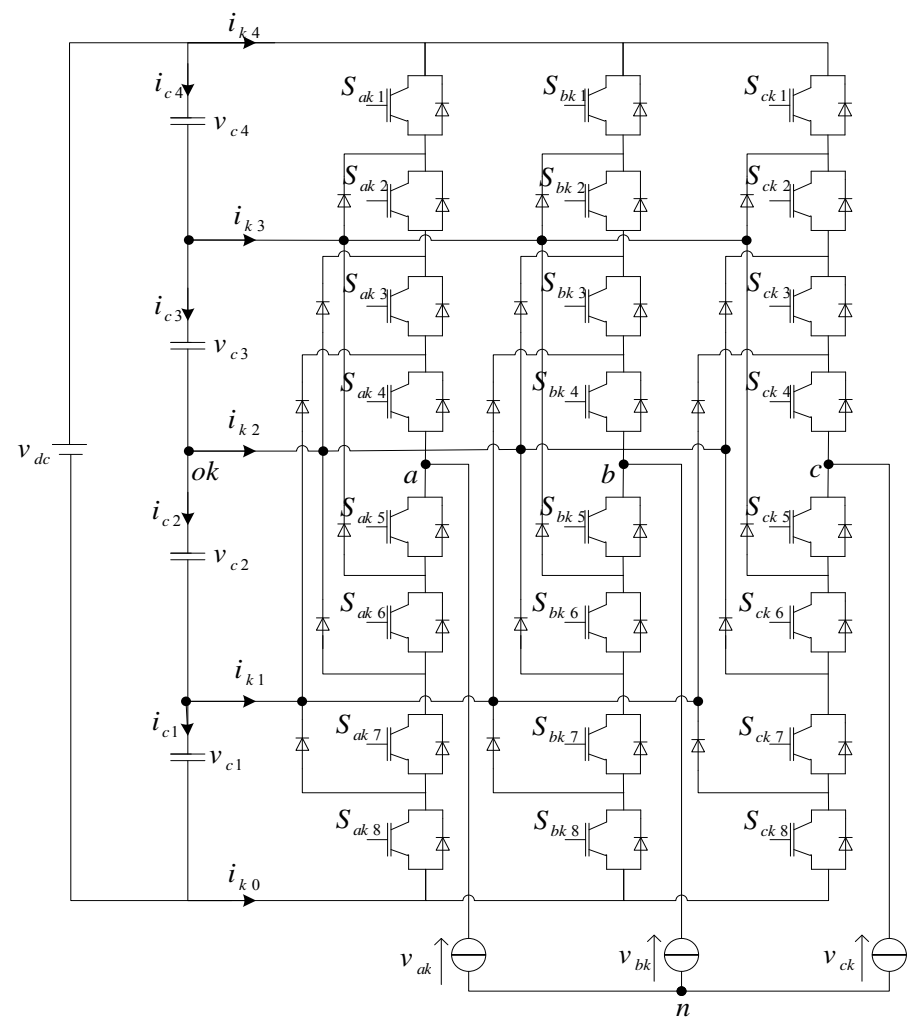

Fig. 2 Structure of a five-level DCI inverter $(k=1$ for first inverter and $k=2$ for second inverter).

Table 1 shows the output voltage levels and the corresponding switch states for one phase of the chosen fivelevel DCI. The switches are arranged into four pairs $\left(S_{x k i}, S_{x k(i+4)}\right)$. If one switch of the pair is turned on, the complementary switch of the same pair must be off. Four switches are triggered at any point of time to select the desired level in the five-level inverter.

\begin{tabular}{|c|c|c|c|c|c|c|c|c|c|}
\hline State & $S_{x k 1}$ & $S_{x k 2}$ & $S_{x k 3}$ & $S_{x k 4}$ & $S_{x k 5}$ & $S_{x k 6}$ & $S_{x k}$ & $S_{x k 8}$ & $v_{x k o}$ \\
\hline 4 & 1 & 1 & 1 & 1 & 0 & 0 & 0 & 0 & $v_{c 3}+v_{c 4}$ \\
\hline 3 & 0 & 1 & 1 & 1 & 1 & 0 & 0 & 0 & $v_{c 3}$ \\
\hline 2 & 0 & 0 & 1 & 1 & 1 & 1 & 0 & 0 & 0 \\
\hline 1 & 0 & 0 & 0 & 1 & 1 & 1 & 1 & 0 & $-v_{c 2}$ \\
\hline 0 & 0 & 0 & 0 & 0 & 1 & 1 & 1 & 1 & $-\left(v_{c 1}+v_{c 2}\right)$ \\
\hline
\end{tabular}

Table 1 Switching state of a five-level DCI $(x=a, b$ or $c)$.
The output voltages of inverter can be written as:

$$
\left[\begin{array}{l}
v_{a k} \\
v_{b k} \\
v_{c k}
\end{array}\right]=\left[\begin{array}{lllll}
F_{c a k 1} & F_{c a k 2} & F_{c c k} 3 & F_{c a k} 4 & F_{c a k} 5 \\
F_{c b k 1} & F_{c b k 2} & F_{c b k} 3 & F_{c b k} 4 & F_{c b k} 5 \\
F_{c c k 1} & F_{c c k 2} & F_{c c k 3} & F_{c c k 4} & F_{c c k} 5
\end{array}\right]\left\lfloor\begin{array}{c}
v_{c 3}+v_{c 4} \\
v_{c 3} \\
0 \\
-v_{c 2} \\
-\left(v_{c 1}+v_{c 2}\right)
\end{array}\right]
$$

With:

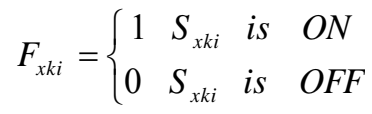

\section{Direct Torque Control Strategy}

Direct torque control is a control technique used in $\mathrm{AC}$ drive systems to obtain high performance torque control. The conventional DTC drive contains a pair of hysteresis comparators, a flux and torque estimator and a voltage vector selection table. The torque and flux are controlled simultaneously by applying suitable voltage vectors, and by limiting these quantities within their hysteresis bands; decoupled control of torque and flux can be achieved.

The stator voltage estimator can be obtained by the following equation:

$\left[\begin{array}{l}\hat{v}_{s \alpha} \\ \hat{v}_{s \beta}\end{array}\right]=[A]\left[\begin{array}{l}\hat{v}_{s 1} \\ \hat{v_{s 2}}\end{array}\right]$

with

$\hat{v}_{s 1}=\left[\begin{array}{lll}\hat{v}_{s a 1} & \hat{v}_{s b 1} & \hat{v}_{s c 1}\end{array}\right]$ and $\hat{v}_{s 2}=\left[\begin{array}{lll}\hat{v}_{s a 2} & \hat{v}_{s b 2} & \hat{v}_{s c 2}\end{array}\right]$

The expression of the stator flux is estimated by:

$$
\left\{\begin{array}{l}
\hat{\phi}_{s \alpha}=\int_{0}^{t}\left(v_{s \alpha}-R_{s} i_{s \alpha}\right) d \tau+\hat{\phi}_{s \alpha}(0) \\
\hat{\phi}_{s \beta}=\int_{0}^{t}\left(v_{s \beta}-R_{s} i_{s \beta}\right) d \tau+\hat{\phi}_{s \beta}(0)
\end{array}\right.
$$

Using (9), the electromagnetic torque is estimated by:

$$
\hat{T}_{e m}=p\left(\hat{\phi}_{s \alpha} i_{s \beta}-\hat{\phi}_{s \beta} i_{s \alpha}\right)
$$

The magnitude of stator flux is estimated by:

$$
\left|\hat{\phi}_{s}\right|=\sqrt{\hat{\phi}_{s \alpha}^{2}+\hat{\phi}_{s \beta}^{2}}
$$

The flux angle is given by: 
$\hat{\theta}_{s}=\operatorname{tag}\left(\frac{\hat{\phi}_{s \beta}}{\hat{\phi}_{s \alpha}}\right)^{-1}$

The switching states of the five-level DCI are presented in Fig. 3.

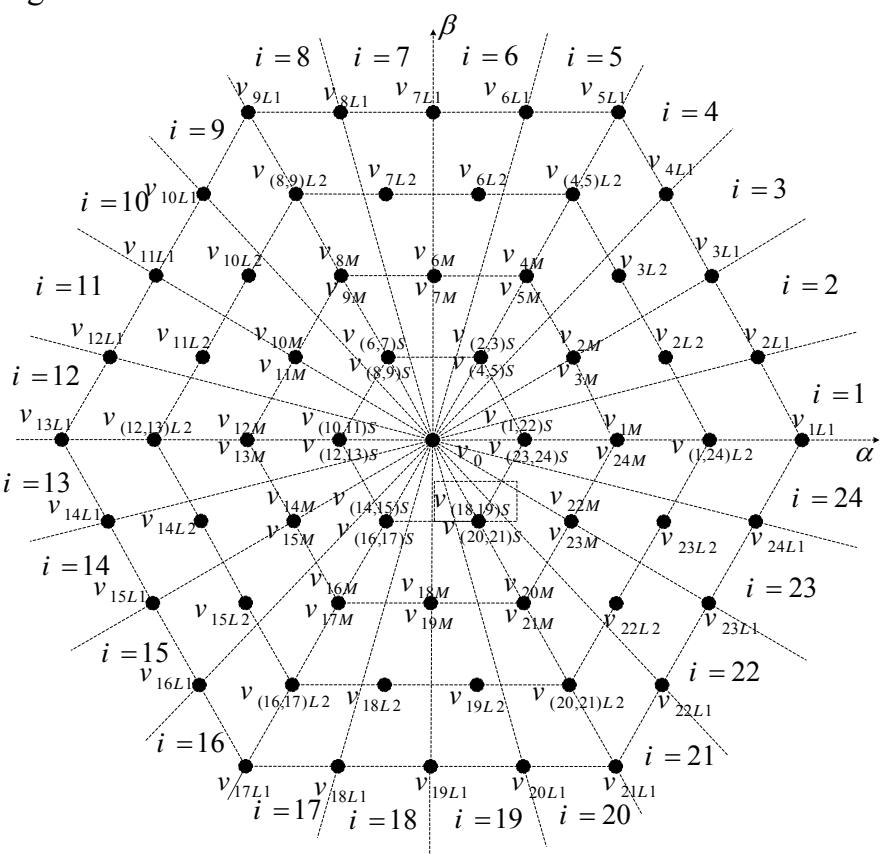

Fig. 3 switching states of the five-level DCI.

The switching tables used in the DTC of first and second DSIM stars are given by Tables (2) and (3), respectively.

\begin{tabular}{|l|l|l|}
\hline$\Phi$ & $\tau$ & Zone $(i)$ \\
\hline \multirow{5}{*}{1} & 4 & $v_{(i+4) L 1}$ \\
\hline \multirow{4}{*}{3} & $v_{(i+4) L 2}$ \\
\cline { 2 - 3 } & 2 & $v_{(i+4) M}$ \\
\cline { 2 - 3 } & 1 & $v_{(i+4) S}$ \\
\cline { 2 - 3 } & 0 & $v_{0}$ \\
\cline { 2 - 3 } & -1 & $v_{(i+20) S}$ \\
\cline { 2 - 3 } & -2 & $v_{(i+20) M}$ \\
\cline { 2 - 3 } & -3 & $v_{(i+20) L 2}$ \\
\hline & -4 & $v_{(i+20) L 1}$ \\
\hline
\end{tabular}

\begin{tabular}{|c|l|l|}
\hline$\Phi$ & $\tau$ & Zone $(i)$ \\
\hline \multirow{4}{*}{0} & 4 & $v_{(i+6) L 1}$ \\
\hline 3 & $v_{(i+6) L 2}$ \\
\hline \multirow{4}{*}{2} & $v_{(i+6) M}$ \\
\hline & 1 & $v_{(i+6) S}$ \\
\cline { 2 - 3 } & 0 & $v_{0}$ \\
\cline { 2 - 3 } & -1 & $v_{(i+18) S}$ \\
\hline-2 & $v_{(i+18) M}$ \\
\hline & -3 & $v_{(i+18) L 2}$ \\
\hline-4 & $v_{(i+18) L 1}$ \\
\hline
\end{tabular}

\begin{tabular}{|l|l|l|}
\hline$\Phi$ & $\tau$ & Zone $(i)$ \\
\hline \multirow{5}{*}{-1} & 4 & $v_{(i+8) L 1}$ \\
\hline \multirow{5}{*}{3} & $v_{(i+8) L 2}$ \\
\hline 2 & $v_{(i+8) M}$ \\
\hline 1 & $v_{(i+8) S}$ \\
\hline 0 & $v_{0}$ \\
\hline & -1 & $v_{(i+16) S}$ \\
\hline-2 & $v_{(i+16) M}$ \\
\hline-3 & $v_{(i+16) L 2}$ \\
\hline-4 & $v_{(i+16) L 1}$ \\
\hline
\end{tabular}

Table 2 Switching table used in the DTC of the first DSIM star.
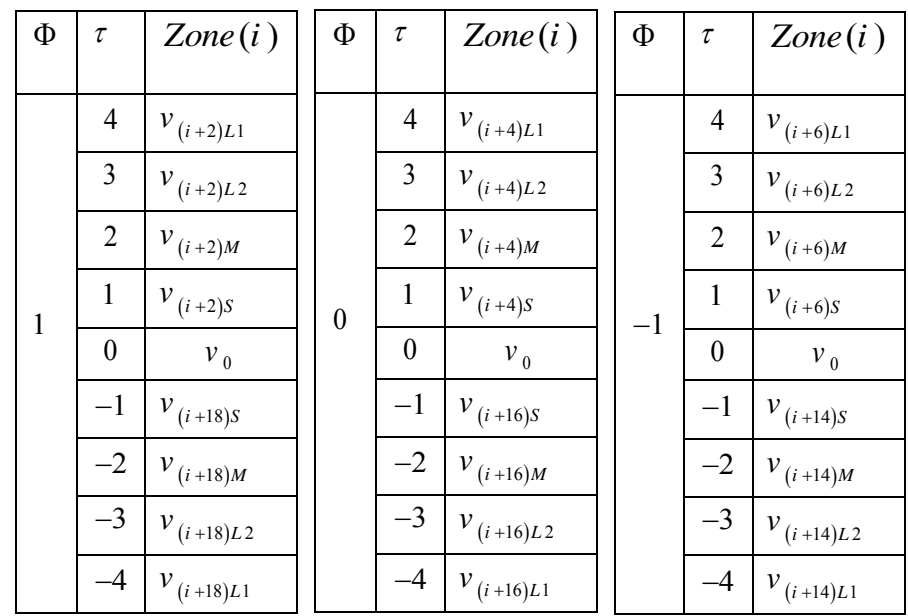

Table 3 Switching table used in the DTC of second DSIM star.

The direct torque control of double star induction motor supplied by two five-level DCI is represented by Fig. 4.

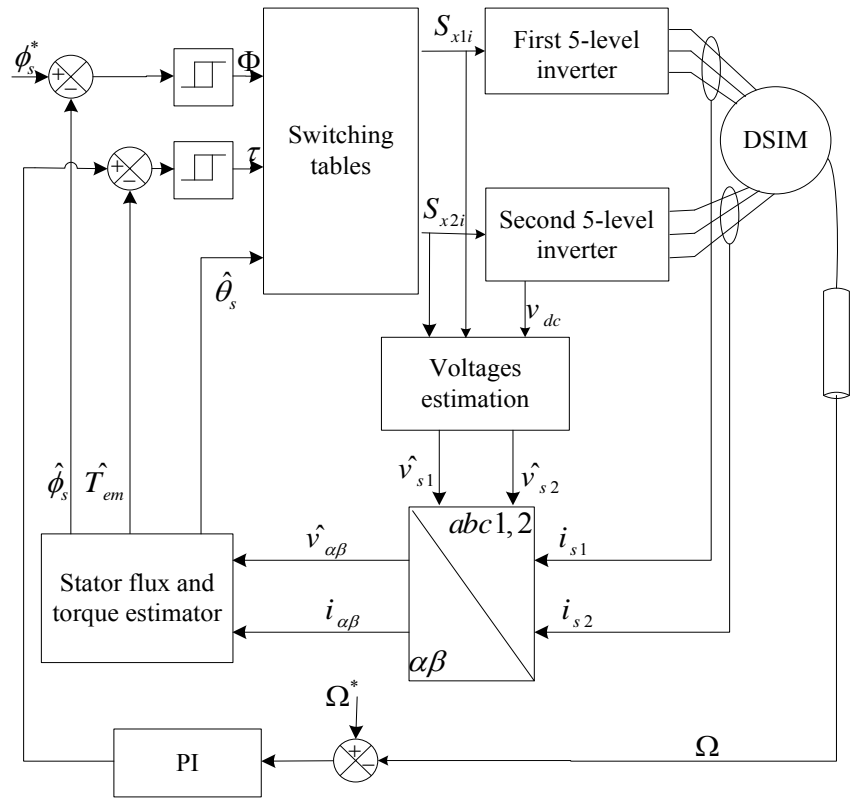

Fig. 4 Five-level DTC scheme without balancing strategy.

\section{Simulation Results OF FiVE-LEVEl DTC WITHOUT BALANCING STRATEGY}

To verify the validity of the five-level DTC strategy, the system was simulated using the DSIM parameters given in Appendix. The simulation results are obtained using the following DC-link capacitance values $C_{1}=C_{2}=C_{3}=C_{4}=1 \mathrm{mF}$. The DC side of the inverter is supplied by a constant DC source $v_{d c}=600 \mathrm{~V}$.

The obtained results are presented in Fig. 5 where the DSIM is accelerated from standstill to reference speed $100 \mathrm{rad} / \mathrm{s}$. The system is simulated with load torque $\left(T_{L}=10 \mathrm{~N} . \mathrm{m}\right)$, afterwards a step variation on the rated load $\left(T_{L}=0 \mathrm{~N} . \mathrm{m}\right)$ is introduced at time $\mathrm{t}=0.5 \mathrm{~s}$. And then a sudden reversion in the speed command from $100 \mathrm{rad} / \mathrm{s}$ to $-100 \mathrm{rad} / \mathrm{s}$ is introduced at $\mathrm{t}=1 \mathrm{~s}$. 

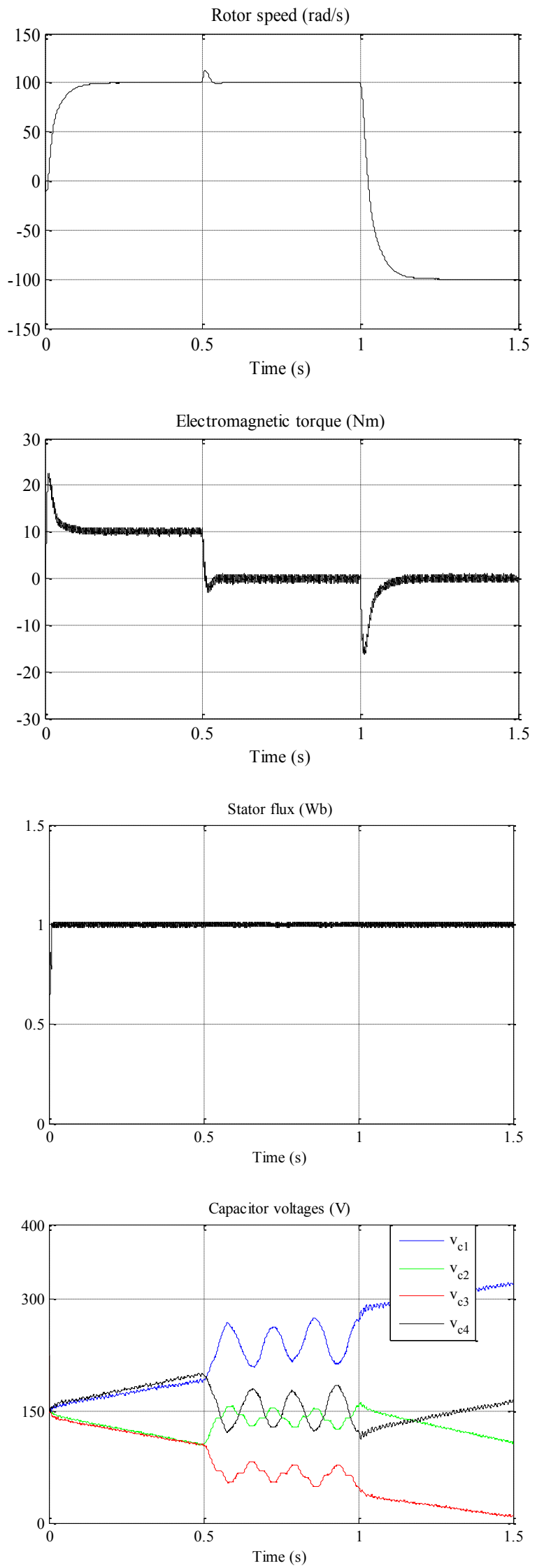

Fig. 5 Five-level DTC performances without balancing strategy for DSIM.
As it can be seen from these figures, the rotor speed response is merged with the reference one and the stator flux is very similar to the nominal case and independent of the torque. Thus, the decoupling between torque and flux is ensured in the beginning and during all the control process. The rotor speed controller intervenes to face the speed variation and ensures that the system follows its suitable reference speed.

It is important to mention the problem of the unbalance of the input DC voltages of the intermediate capacitors filter. Indeed, the voltages $v_{c l}$ and $v_{c 4}$ increase and the voltages $v_{c 2}$ and $v_{c 3}$ decrease. In order to improve the performance of fivelevel DTC for DSIM, a five-level DTC based on balancing mechanism is proposed.

\section{DC-CAPACITOR Voltage BALANCING StRATEgy}

The capacitor voltage balancing strategy proposed in this work is based on the minimum energy property fulfilled by selecting appropriate redundant switching states of the two DCI units over a switching period [11].

In a five-level DCI, the total energy $E$ of the four capacitors is:

$$
E_{k}=\frac{1}{2} \sum_{j=1}^{4} C_{j} v_{c j}
$$

To achieve voltage balancing a control method should minimize (13) [8]. By a change of variable from $v_{c j}$ to $\left(v_{c j}-v_{d c}\right) / 4$ in (13) the positive definite cost function becomes:

$$
J=\frac{1}{2} C \sum_{j=1}^{4} \Delta v_{c j}^{2}
$$

where $\Delta v_{c j}$ is the voltage deviation of capacitor $C_{j}$ defined by:

$$
\Delta v_{c j}=v_{c j}-v_{d c} / 4
$$

Based on a proper selection of redundant vectors, $J$ can be minimized if the capacitor voltages are maintained at voltage reference values of $\left(\mathrm{v}_{d c} / 4\right)$.

The mathematical condition to minimize $J$ is:

$$
\frac{d J}{d t}=C \sum_{j=1}^{4} \Delta v_{c j} \frac{d v_{c j}}{d t}=\sum_{j=1}^{4} \Delta v_{c j} i_{c j}
$$

with $i_{c k j}$ is the current through capacitor $C_{j}$.

The capacitor currents $i_{c k j}$ in (16) are affected by the DCside intermediate branch currents $i_{k 3}, i_{k 2}$ and $i_{k 1}$. Currents $i_{k 3}, i_{k 2}$ and $i_{k 1}$ can be calculated if the switching states used in the switching pattern are known. Thus, it is advantageous to 
express (16) in terms of $i_{k 3}, i_{k 2}$ and $i_{k 1}$.

The DC-capacitor currents are expressed as:

$$
i_{c j}=\frac{1}{4} \sum_{y=1}^{3} y\left(\sum_{k=1}^{2} i_{k y}\right)-\sum_{y=j}^{3}\left(\sum_{k=1}^{2} i_{k y}\right)
$$

By substituting $i_{c k j}$ calculated from (17) in (16), the condition to achieve voltage balancing becomes:

$$
\sum_{j=1}^{4} \Delta v_{c j}\left(\frac{1}{4} \sum_{y=1}^{3} y\left(\sum_{k=1}^{2} i_{k y}\right)-\sum_{y=j}^{3}\left(\sum_{k=1}^{2} i_{k y}\right)\right) \leq 0
$$

Since the net DC-link voltage is regulated at $v_{d c}$

$$
\sum_{j=1}^{4} \Delta v_{c j}=0
$$

Substituting $\Delta v_{c 4}$ calculated from (19), in (18) yields

$$
\sum_{j=1}^{3} \Delta v_{c j}\left(\sum_{y=j}^{3}\left(\sum_{k=1}^{2} i_{k y}\right)\right) \geq 0
$$

By applying the averaging operator, over one sampling period, to (20) it results:

$$
\frac{1}{T} \sum_{K T}^{(K+1) T} \Delta v_{c j}\left(\sum_{y=j}^{3}\left(\sum_{k=1}^{2} i_{k y}\right)\right) d t \geq 0
$$

Equation (21) can be simplified to:

$$
\sum_{j=1}^{3} \Delta v_{c j}(K)\left(\sum_{y=j}^{3}\left(\sum_{k=1}^{2} \bar{i}_{k y}\right)(K)\right) d t \geq 0
$$

where:

$\Delta v_{c j}(K)$ : The voltage drifts of $C_{j}$ at sampling period $K$.

$\bar{i}_{k y}(K):$ The averaged value of the $j^{\text {th }}$ DC-side intermediate branch current.

To calculate $\overline{i_{k y}}(y=1, \ldots, 3)$ contributions of switching states to the DC side intermediate branch currents and relationship between the $\mathrm{DC}$ and $\mathrm{AC}$ side currents, $i_{k a}, i_{k b}$, and $i_{k c}$, are required.

$$
\left\{\begin{array}{l}
i_{k 3}=F_{C a k} i_{a k}+F_{C b k} i_{b k}+F_{C c k 3} i_{c k} \\
i_{k 2}=F_{C a k 2} i_{a k}+F_{C b k 2} i_{b k}+F_{C c k} i_{c k} \\
i_{k 1}=F_{C a k 1} i_{a k}+F_{C b k 1} i_{b k}+F_{C c k 1} i_{c k}
\end{array}\right.
$$

$$
J_{k}=\sum_{j=1}^{3} \Delta v_{c j}(K)\left(\sum_{y=j}^{3}\left(\sum_{k=1}^{2} \bar{i}_{k y}\right)(K)\right)
$$

The currents $\bar{i}_{k y}$ are calculated based on (23) for each set of switching combinations, they are replaced in (24) and the best set that fulfills the condition is selected.

For instance, in the triangle of the first sector where the following switching states: $(421,310),(411,300)$ and (410) are available, the table 4 can be obtained.

\begin{tabular}{|l|l|l|l|l|l|}
\hline$i_{k y}$ & 421 & 310 & 411 & 300 & 410 \\
\hline$i_{k 1}$ & $i_{c k}$ & $i_{b k}$ & $-i_{a k}$ & 0 & $i_{b k}$ \\
\hline$i_{k 2}$ & $i_{b k}$ & 0 & 0 & 0 & 0 \\
\hline$i_{k 3}$ & 0 & $i_{a k}$ & 0 & $i_{a k}$ & 0 \\
\hline
\end{tabular}

Table 4 Example for switching states in the first sector.

Fig. 6 shows a schematic diagram of the five-level DTC balancing system including the DC capacitor voltage control strategy.

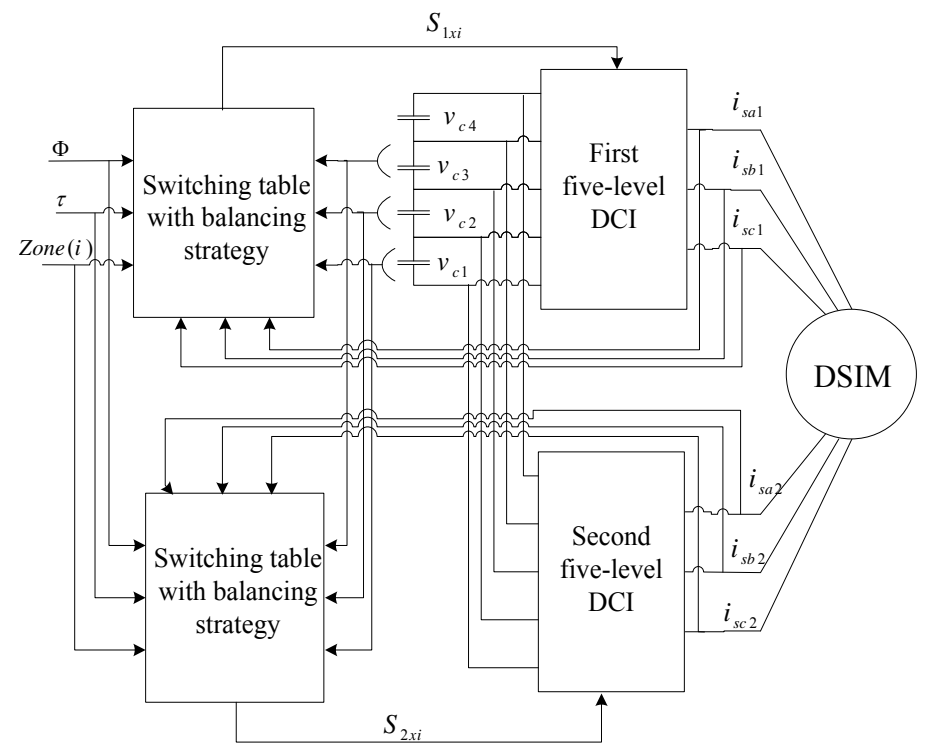

Fig. 6 Schematic representation of the five-level DTC with balancing strategy.

\section{Simulation Results of Five-LEVEl DTC WITH BALANCING STRATEGY}

The proposed multilevel DTC with balancing strategy is tested by some numerical simulations to verify its effectiveness in the steady-state and dynamic. Fig. 7 presents the simulation results obtained in the same conditions as in Fig. 5.

From (23), the cost function can be written: 

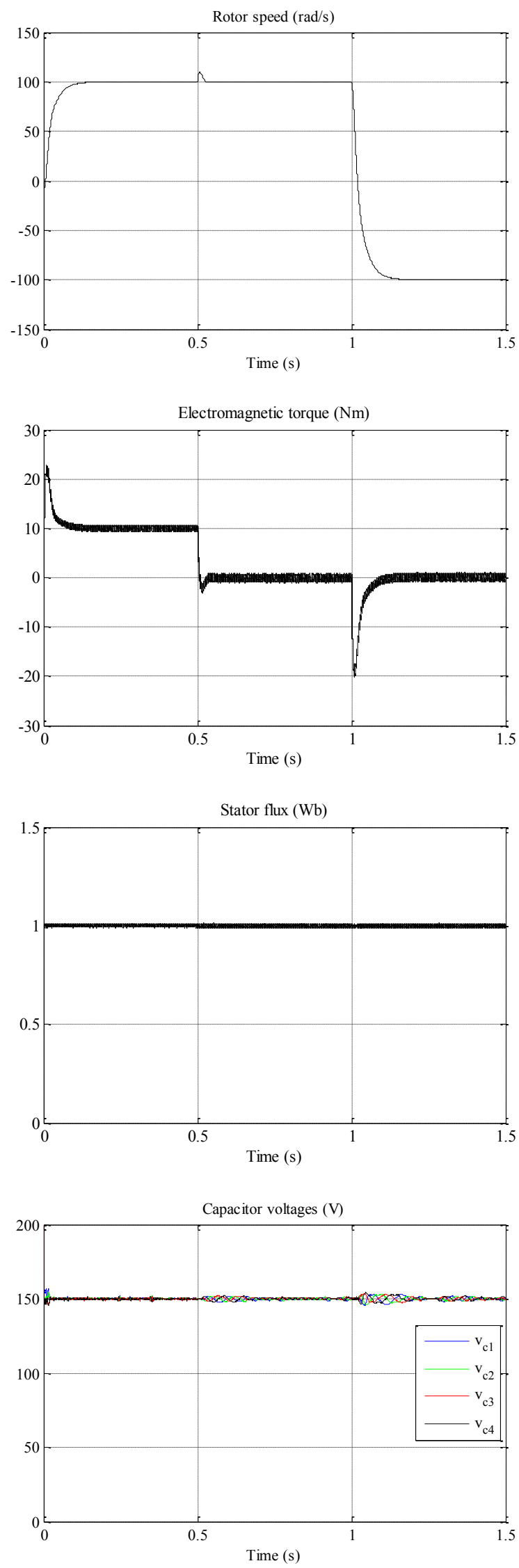

Fig. 7 Five-level DTC performances with balancing strategy for DSIM.
In Fig. 7, as can be seen, the rotor speed follows its reference value while the torque returns to its reference value with a little error. These results show that speed transients lead to the electromagnetic torque variations.

It can be observed also that the proposed DTC with balancing strategy is able to guarantee capacitor voltages balance even during the abovementioned transits. In addition, the tracking capability is further improved, and the decoupling control between electromagnetic torque and stator flux is always confirmed.

\section{CONCLUSION}

The objective of this work was, at first, to realize a direct torque control applied to a double star induction machine fed by two five-level diode-clamped inverters. In the second place, it aims to improve the system overall dynamic performances by introducing DC-link voltage balancing strategy.

The obtained results are very satisfactory since they show a good stability of the DC-link voltages. So, the proposed DTC endowed by a balancing strategy based on the adequate use of the redundant vectors seems to be an effective way to deal with the inverter input DC voltages drift phenomenon.

However, it is worth to mention that the control of the fivelevel diode-clamped inverter is not only known by its complexity but also the DC-link voltage balancing is an extra constrained to fulfill.

\section{APPENDIX}

The parameters of DSIM are given in table 5.

\begin{tabular}{|l|c|c|}
\hline \multicolumn{3}{|c|}{$1 \mathrm{~kW}, 2$ Poles, $220 \mathrm{~V}, 50 \mathrm{~Hz}$} \\
\hline \multicolumn{1}{|c|}{ Quantity } & Symbol & Value \\
\hline Stator resistance & $R_{s}$ & $4.67 \Omega$ \\
\hline Rotor resistance & $R_{r}$ & $8 \Omega$ \\
\hline Stator inductance & $L_{s}$ & $0.374 \mathrm{H}$ \\
\hline Rotor inductance & $L_{r}$ & $0.374 \mathrm{H}$ \\
\hline Mutual inductance & $M$ & $0.365 \mathrm{H}$ \\
\hline Inertia moment & $J$ & $0.003 \mathrm{kgm}^{2}$ \\
\hline
\end{tabular}

Table 5 DSIM parameters.

\section{REFERENCES}

[1] V. Talaeizadeh, R. Kianinezhad, S. Seyfossadat, and H. Shayanfar, "Direct torque control of six-phase induction motors using three-phase matrix converter," Energy Conversion and Management, vol. 51, pp. 2482-2491, 2010.

[2] K. Nounou, M. Benbouzid, K. Marouani1, J. Frédéric, and A. Kheloui, "Performance comparison of open-circuit fault-tolerant control strategies for multiphase permanent magnet machines for naval applications," Electrical Engineering, vol. 100, no. 3, pp. 1827-1836, 2018.

[3] D. Boudana, L. Nezli, A. Tlemcani, M. Mahmoudi and M. Djemai, "DTC based on fuzzy logic control of a double star synchronous machine drive," Nonlinear Dynamics and Systems Theory, vol. 8, no. 3, pp. 269-286, 2008. 
[4] H. Kouki, F. Mouldi, and H. Rehaoulia, "Harmonic analysis of SVPWM control strategy on VSI-fed double-star induction machine performances," Electrical Engineering, vol. 98, no. 2, pp. 133-143, 2016.

[5] A. Panda, and Y. Suresh, "Research on cascade multilevel inverter with single DC source by using three-phase transformers," International Journal of Electric Power Energy System, vol. 40, no. 1, pp. 9-20, 2012.

[6] K. Gayathri, S. Arun, and C. Sreeja, "Comparative study on different five level inverter topologies," Electrical Power and Energy Systems, vol. 63, pp. 363-372, 2014.

[7] B. Sergio, G. Robert, N. Joan, and B. Joseb, "Decoupled DClink capacitor voltage control of DC-AC multilevel multileg converters," IEEE Transaction on Industrial Electronics, vol. 63, no. 3, 2016.

[8] S. Shunji, W. Xiangzhou, Z. Shuhua, Z. Yanxi, and L. Dongyuan, "A new diode-clamped multilevel inverter with balance voltages of DC capacitors," IEEE Transaction on Energy Conversion, vol. 33, no. 4, 2018.

[9] W. Zheng, W. Xueqing, C. Jiawei, C. Ming, and H. Yihua, "Direct torque control of T-NPC inverters-fed double-satatorwinding PMSM drives with SVM," IEEE Transaction on Power Electronics, vol. 33, no. 2, pp. 1541-1553, 2018.

[10] B. Naas, L. Nezli, M. Mahmoudi, and M. Elbar, "Direct torque control based three-level inverter fed double star permanent magnet synchronous machine," Energy Procedia, vol. 18, pp. 521-530, 2012.

[11] M. Saeedifard, R. Iravani, and J. Pou, "Analysis and control of DC-capacitor-voltage-drift phenomenon of a passive front-end five-level converter," IEEE Transactions on Industrial Electronics, vol. 54, no. 6, pp. 3255-3266, 2007.

\section{Creative Commons Attribution License 4.0 (Attribution 4.0 International, CC BY 4.0)}

This article is published under the terms of the Creative Commons Attribution License 4.0

https://creativecommons.org/licenses/by/4.0/deed.en_US 